\title{
In Vitro Assessment of Cardiac Function Using Skinned Cardiomyocytes
}

\author{
Patrícia Gonçalves-Rodrigues ${ }^{*}, 1$, João Almeida-Coelho ${ }^{*},{ }^{1}$, Alexandre Gonçalves ${ }^{1}$, Flávio Amorim ${ }^{1}$, Adelino F. Leite- \\ Moreira $^{1}$, Ger J.M. Stienen ${ }^{2}$, Inês Falcão-Pires ${ }^{1}$ \\ ${ }^{1}$ Unidade de Investigação Cardiovascular, Departamento de Cirurgia e Fisiologia, Faculdade de Medicina, Universidade do Porto ${ }^{2}$ Department of \\ Physiology, Kilimanjaro Christian Medical University College \\ *These authors contributed equally
}

\section{Corresponding Author}

Inês Falcão-Pires

ipires@med.up.pt

\section{Citation}

Gonçalves-Rodrigues, P., Almeida-

Coelho, J., Gonçalves, A., Amorim, F.,

Leite-Moreira, A.F., Stienen, G.J.,

Falcão-Pires, I. In Vitro Assessment

of Cardiac Function Using Skinned

Cardiomyocytes. J. Vis. Exp. (160),

e60427, doi:10.3791/60427 (2020).

\section{Date Published}

June 22, 2020

DOI

$10.3791 / 60427$

URL

\section{Abstract}

In this article, we describe the steps required to isolate a single permeabilized ("skinned") cardiomyocyte and attach it to a force-measuring apparatus and a motor to perform functional studies. These studies will allow measurement of cardiomyocyte stiffness (passive force) and its activation with different calcium $\left(\mathrm{Ca}^{2+}\right)$-containing solutions to determine, amongst others: maximum force development, myofilament $\mathrm{Ca}^{2+}$-sensitivity (pCa50), cooperativity (nHill) and the rate of force redevelopment (ktr). This method also enables determination of the effects of drugs acting directly on myofilaments and of the expression of exogenous recombinant proteins on both active and passive properties of cardiomyocytes. Clinically, skinned cardiomyocyte studies highlight the pathophysiology of many myocardial diseases and allow in vitro assessment of the impact of therapeutic interventions targeting the myofilaments. Altogether, this technique enables the clarification of cardiac pathophysiology by investigating correlations between in vitro and in vivo parameters in animal models and human tissue obtained during open heart or transplant surgery.

jove.com/video/60427

\section{Introduction}

Traditionally, assessment of myocardial mechanical properties has been attempted mostly in multicellular preparations, such as papillary muscles and trabeculae $e^{1,2}$. Multicellular cardiac muscles strips include a heterogeneous population of cells, including contractile cardiomyocytes with an unknown pattern of orientation and force generation, electrical activity and stress/strain distributions as well as a surrounding connective tissue matrix ${ }^{3,4}$. A preparation without collagen and containing a single cardiomyocyte would allow measurement of sarcomere length and crossbridge contractile properties in a very precise and controlled manner ${ }^{5,6}$. Therefore, over the last four decades, several methodologies were developed allowing investigating the mechanical, contractile, and relaxation properties of a single 
cardiomyocyte $e^{6,7}$. The contractile function of these cells is strongly dependent on sarcomere length and cross-bridge cycling kinetics ${ }^{3}$. Thus, it is desirable to investigate muscle function directly in single isolated cardiac cells, considering that it allows assessing sarcomere length and performance as well as cross-bridge function and contractile properties. However, isolating and attaching functional cardiomyocytes with a reasonable optical sarcomere resolution while recording force measurement at the $\mu \mathrm{N}$ level is still challenging and evolving ${ }^{3,6}$. Other challenges are the logistics that need to be installed to isolate cardiomyocytes from freshly collected biopsies. The unpredictability of human biopsies collection, for instance, may jeopardize the feasibility of the experiments.

Moreover, ethical concerns regarding the Replacement, Reduction and Refinement of animal experimentation for scientific procedures (principles of the 3Rs) have promoted study changes at the cellular and tissue level, preferably in human biopsies, or in smaller animal samples. Indeed a progressive refinement of methodologies to assess cardiac function in vitro on a smaller level of complexity allows proper integration of the results to the whole body and translate them to the clinical scenario ${ }^{7}$. Altogether, using samples stored at $-80^{\circ} \mathrm{C}$ to extract cardiomyocytes may be an appealing alternative.

The myocardial tissue is cut into small pieces and homogenized with a mortar and a pestle. The result of this homogenization is a suspension of skinned bundled and isolated cells with varying degrees of sarcolemmal damage, wherein the myoplasm is exposed to the bathing medium and all the cellular components are washed out. Structures such as the myofibrils that are further away from the sarcolemma are preserved. Thus, sarcomere shortening and functional properties associated with the myofibrillar apparatus are kept intact and can be recorded 8,9 .

The cardiomyocyte force measurement system consists of an electromagnetic motor, used to adjust cardiomyocyte length, and a force transducer, that measures isometric cardiomyocyte contraction. A permeabilized, or skinned, cardiomyocyte is placed in an experimental chamber containing a relaxing solution $\left(\left[\mathrm{Ca}^{2+}\right]<10 \mathrm{nM}\right)$ and siliconglued to 2 thin needles: one attached to the motor and the other to the force transducer. An optical system is used to determine cardiomyocyte morphology and sarcomere length. The experimental protocol often consists of a series of force recordings upon buffer solutions containing different $\mathrm{Ca}^{2+}$ concentrations, the determination of actin-myosin cross-bridge kinetics and the measurement of the passive tension of the mounted cardiomyocytes at pre-defined sarcomere lengths (Figure 1). Isolation of permeabilized cardiomyocytes from myocardial samples frozen in liquid nitrogen (and subsequently stored at $-80^{\circ} \mathrm{C}$ ) is a technique that utilizes cellular mechanics and protein biochemistry for measuring maximal $\mathrm{Ca}^{2+}$-activated (active) force per cross-sectional area $\left(\mathrm{T}_{\text {active }}, \mathrm{kN} \cdot \mathrm{m}^{-2}\right), \mathrm{Ca}^{2+}$-independent (passive) tension ( $T$ passive, $\mathrm{kN} \cdot \mathrm{m}^{-2}$ ), myofilaments $\mathrm{Ca}^{2+}$ sensitivity (pCa50), myofilaments cooperativity (nHill), the rate of force redevelopment ( $\mathrm{ktr}$ ) as well as sarcomere length dependencies of Tactive, Tpassive, pCa50, nHill and ktr.

The goal of this protocol is to illustrate and summarize the potential of the cardiomyocyte force measurement system as a reliable procedure to assess the functional mechanical properties of single skinned cardiomyocytes isolated from frozen samples from different species. 


\section{Protocol}

All animal experiments comply with the Guide for the Care and Use of Laboratory Animals (NIH Publication no. 85-23, revised 2011) and the Portuguese law on animal welfare (DL 129/92, DL 197/96; P 1131/97). The competent local authorities approved this experimental protocol (018833).

\section{Stock solution preparation (Table 1)}

1. Prepare $1,000 \mathrm{~mL}$ of relaxing solution for cardiomyocytes' isolation (RELAX-ISO) by following instructions in Table

2. Dissolve the reagent above in $\approx 500 \mathrm{~mL}$ and adjust the $\mathrm{pH}$ to 7.0 with $\mathrm{KOH}$. Adjust the final volume to $1000 \mathrm{~mL}$.

1. Distribute RELAX-ISO in $50 \mathrm{~mL}$ tubes. Store at $-20^{\circ} \mathrm{C}$.

2. Prepare $250 \mathrm{~mL}$ of activating solution by following the instructions in Table 3. Dissolve the reagents above in $\approx 100 \mathrm{~mL}$ of ultra-pure water. Adjust the $\mathrm{pH}$ to 7.1 with 5 $\mathrm{M} \mathrm{KOH}$ at $15^{\circ} \mathrm{C}$.

NOTE: Usually, it is necessary to add a significant amount of $\mathrm{KOH}$ to reach the desired $\mathrm{pH}$. Put the volumetric balloon in a box with ice to cool down the solution to $15^{\circ} \mathrm{C}$.

1. Adjust the final volume to $250 \mathrm{~mL}$. Agitate this solution continuously with a magnetic stirrer until the moment of mixing it with the relaxing solution.

3. Prepare $100 \mathrm{~mL}$ of relaxing solution by following the instructions in Table 4. Dissolve the reagents above in $\approx 50 \mathrm{~mL}$ of ultra-pure water. Adjust the $\mathrm{pH}$ to 7.1 with $\mathrm{KOH}$ $5 \mathrm{M}$ at $15^{\circ} \mathrm{C}$.

NOTE: Usually, it is necessary to add a significant amount of $\mathrm{KOH}$ to reach a $\mathrm{pH}$ of 7.1. Place the volumetric balloon in a box filled with ice to cool down the solution to $15^{\circ} \mathrm{C}$. The ionic strength of the solutions used during the measurements amounted to $180 \mathrm{mM}$.
1. Adjust the final volume to $100 \mathrm{~mL}$. Agitate this solution continuously with a magnetic stirrer until the moment of mixing it with activating solution.

4. Mix activating and relaxing solutions in the proportions presented in Table 5 to obtain pCa solutions between 5.0 and 6.0.

1. Always keep relaxing and activating solutions agitating while mixing both.

2. Aliquot each mixture to $2 \mathrm{~mL}$ microtubes. Store all the microtubes at $-20^{\circ} \mathrm{C}$.

5. Prepare a different batch of pCa solution (4.5 to 6.0$)$ for each protocol.

\section{Calibration of the force transducer}

NOTE: The calibration of the force transducer is a routine procedure that should be performed every couple of months or whenever it is suspected to be uncalibrated. The force transducer is highly sensitive and is easily broken. It should be gently handled in every step of its usage, including calibration, gluing of the cardiomyocyte and cleaning.

1. Detach the force transducer from the rest of the apparatus.

2. With the help of a clamp, place the force transducer horizontally in such a way that the needle points downward in the same orientation that the cardiomyocyte will develop force. This will facilitate hanging a series of masses with known weights (elastic band, suture or pin). NOTE: Check the characteristics of the force transducer before proceeding to this step to check the scale factor [mg/volt] and to avoid excessive weight on the transducer. For the force transducer model, the scale factor is 50 (50 
$\mathrm{mg}$ correspond to 1 volt) and we use 5 weights between 12.5 and $250 \mathrm{mg}$.

3. Turn the force transducer on and let it warm up for $30 \mathrm{~min}$.

4. Start by hanging the lighter mass on the force transducer and registering the corresponding voltage measured at FORCE OUT.

1. Repeat this procedure for up to five weights.

5. Plot force applied to the force transducer (load) versus voltage and check for linearity.

6. If there is no linearity, adjust the zero and gain potentiometers in the circuit board of the transducer. Check its specific instruction for further information.

1. Turn the zero potentiometer until the output voltage reads $0.0 \mathrm{~V}$.

2. Hand a medium weight on the transducer needle and adjust the gain potentiometer to read the corresponding voltage (for instance, $50 \mathrm{mg}$ correspond to $1 \mathrm{~V}$ ). Remove the weight and re-adjust the zero potentiometer to 0.0 .

3. Repeat step 2.6 .2 until the output with and without the weight are correct.

7. Mount the force transducer back into the apparatus.

\section{Setting the experimental apparatus}

1. Thaw one vial of each of the activating, $4.5,5.0,5.2,5.4$, $5.6,5.8,6.0$ and relaxing solutions and maintain them on ice.

NOTE: ATP and PCr are labile compounds that should be maintained at cold temperatures.

2. Prepare the microscope, testing apparatus and associated computer for use (Figure 1).
3. Adjust the temperature so that the in-chamber thermometer reads $15{ }^{\circ} \mathrm{C}$. Perform all experiments at this temperature except for kinase and phosphatase incubations $\left(20^{\circ} \mathrm{C}\right)$.

4. Turn on the force-transducer and the motor.

\section{Extraction and permeabilization of skinned cardiomyocytes}

1. Defrost $50 \mathrm{~mL}$ of RELAX-ISO solution.

2. Turn on the centrifuge and fast cool it up to $4{ }^{\circ} \mathrm{C}$.

3. Thaw 3-5 $\mu \mathrm{g}$ of a myocardial sample in a Petri dish containing $2.5 \mathrm{~mL}$ of RELAX-ISO solution.

4. Cut the tissue in small pieces with a scalpel blade (Figure 2). Cut the sample in a precise way to avoid unnecessary cells damage.

5. Transfer the $2.5 \mathrm{~mL}$ of RELAX-ISO solution with the tissue to a Potter-Elvehjem glass using a cut pipette tip.

6. Mechanically disrupt the tissue with a grinder at a rotation speed of 30-40 rpm. Press the tissue 3 times for $2 \mathrm{~s}$ each to obtain a good cell suspension.

7. Prepare $10 \%$ Triton in RELAX-ISO solution $(250 \mu \mathrm{L}$ of Triton with $2.25 \mathrm{~mL}$ of RELAX-ISO) in a $15 \mathrm{~mL}$ tube and add this solution to the cell suspension.

8. Gently mix by inverting the tube 3 times.

9. Incubate at room temperature for $1 \mathrm{~min}$ and $4 \mathrm{~min}$ on ice.

10. Wash out the Triton by adding RELAX-ISO up to the top of the $15 \mathrm{~mL}$ tube; gently mixing (inverting 3 times the tube) and finally spinning down the cells in an angled centrifuge $(1 \mathrm{~min}$ at $348 \times g)$. Remove the supernatant up to $3 \mathrm{~mL}$ above the cell pellet. 
NOTE: Remove the supernatant gently to avoid disturbing the cell pellet. Still, some cells in supernatant will be inevitably lost.

11. Repeat the step 4.10 at least 4 times or until no more bubbles produced by Triton residues are observed.

NOTE: The more wash-out steps are made, the more cells are lost with the discarded supernatant.

12. In the last wash-out, remove the supernatant up to a volume of $5-10 \mathrm{~mL}$ of cell suspension.

\section{Selecting and gluing the skinned cardiomyocyte}

1. Put a cell suspension drop on a coverslip on top of a glass slide in the microscope slide holder (Figure 1).

2. Select a single rod-shaped cardiomyocyte with a good striation pattern and size (Figure 2).

3. Find the needle tips of the force-transducer and the motor using the lowest magnification of the inverted microscope.

4. Rotate the coverslip to position the selected cardiomyocyte horizontally so that its ends are aligned with the needle of the force transducer and the motor (Figure 2).

5. Place a thin line of glue on the side of the coverslip with the help of a swab tip (Figure 2).

6. Immerse the needle tips of the force transducer and the motor into the glue line to create a glue halo around both tips.

NOTE: Steps 5.6 - 5.10 are accomplished through careful use of the motorized micropositioners.

7. Quickly move the needle tips close to the focal plane of the cardiomyocyte.

8. Move the needle tip of the force transducer down so that it glues to one edge of the cardiomyocyte.
9. Repeat this procedure with the tip of the motor and the other extremity of the cell.

NOTE: This procedure must take less than 2-3 min as the glue starts to cure very fast.

10. After $5-8 \mathrm{~min}$, lift the needles $\approx 15 \mu \mathrm{m}$ to avoid gluing the cell to the coverslip. This is done by moving up both micromanipulators simultaneously.

11. Let the glue cure. This procedure can last from 15 to 45 min, depending on the type of glue. In our case, the cardiomyocyte is adequately glued after $\approx 15 \mathrm{~min}$.

\section{Recording force measurements of active, passive and $\mathrm{Ca}^{2+}$ sensitivity}

1. Fill the first experimental well with the relaxing solution (55-100 $\mu \mathrm{L}$ in the experimental apparatus) and the second experimental well with activating solution.

2. Using the camera software, place the region of interest $(\mathrm{ROI})$ in an area of the cardiomyocyte with a clear pattern of striation.

NOTE: For cardiac myocytes, the operating sarcomere length varies between 1.8 and $2.2 \mu \mathrm{m}$, and the optimal sarcomere length is around $2.15 \mu \mathrm{m}$.

3. Measure the distance between the two extremes of the cardiomyocyte (from the motor to the transducer glue halo, Figure 3) after the optimal sarcomere length has been set $(2.2 \mu \mathrm{m})$. Record the value as myocyte length in the software.

4. Measure cardiomyocyte width and depth, the latter with the aid of a prism mirror placed perpendicular to the cell. NOTE: A powerful, external light source will be required to visualize the cell through the prism. In case there is no prism, and assuming that cardiac cells have an elliptical 
shape, cardiomyocyte depth can be inferred as $70 \%$ of cardiomyocyte width.

5. Calculate cross-sectional area (CSA, $\mathrm{mm}^{2}$ ) assuming an elliptical shape of the cardiomyocyte.

$\mathrm{CSA}=\pi *\left(\frac{\text { width }}{2 * 1000}\right) *\left(\frac{\text { depth }}{2 * 1000}\right)$

6. Gently move the microscope stage so that the cell moves from the coverslip to the well containing relaxing solution on the back of the stage.

NOTE: This procedure can easily damage the cell. Before moving the cell, gently move the needles up a bit more. Avoid removing the cell out of the solution.

7. Select the protocol in software that contains two cell shortening ( $80 \%$ of its initial length), that will occur when the cell is emerged in $\mathrm{Ca}^{2+}$ solution and in relaxing solution, respectively (Figure 1, Supplementary File).

NOTE: First "Slack" of the cell will be performed within activating solution and the second "Slack" within relaxing solution. By doing this, the user will be able to calculate the total force $\left(F_{\text {total }}\right)$ of the cell from the $1^{\text {st }}$ and the passive force ( $F$ passive $)$ of the cell from the $2^{\text {nd }}$. Use the formula to calculate active force, $F_{\text {active }}=$ Ftotal Fpassive. The cell is shortened $80 \%$ in order to detach all cross-bridges record force.

8. Elicit isometric contraction by moving the microscope stage so that the cardiomyocyte moves from the relaxing to the activating solution $(\mathrm{pCa}=4.5(1))$.

NOTE: If the cell is functional, it will immediately contract.

9. Upon reaching force plateau, start recording the force data.

NOTE: The tests can be done individually. Depending on software there is the possibility to create a sequence of tests that will correspond to the different $\mathrm{Ca}^{2+}$ solutions within a $\mathrm{Ca}^{2+}$-sensitivity protocol (Figure 1, Supplementary File).

10. Wait $\sim 10 \mathrm{~s}$ and then switch the cell immersed in activating solution.

NOTE: It is important to wait $10 \mathrm{~s}$ before immersing the cell in relaxing solution. If the cell is moved too early, important data to calculate the redevelopment force of the cell (ktr value) might be lost.

11. Quickly move the stage so that the cardiomyocyte immerses in the relaxing solution.

12. Wait until the test stops.

13. Repeat steps $6.8-6.12$ so that the cell is activated twice in activating solution ( $\mathrm{pCa}=4.5(2))$.

NOTE: Typically, after the first activation, cardiomyocyte ends can slightly detach from the needle tips, changing the cardiomyocyte length, CSA and/or the sarcomere length. Readjust to the desired sarcomere length and introduce the corrected dimensions in the software.

1. Continue to step 6.13 .2 for $\mathrm{Ca}^{2+}$ sensitivity protocol or save the data, if values of passive and active force of the cell are the only parameters needed and detach the cell from needles and clean them with acetone to remove the glue.

2. Adjust the sarcomere length of the cell to $2.2 \mu \mathrm{m}$ by slightly stretching it again, if necessary.

3. Replace the activating solution by the next $\mathrm{Ca}^{2+}$ solution (55-100 $\mu \mathrm{L}$ here). Repeat steps 6.8 - 6.12.

4. Replace the activating solution by the next $\mathrm{Ca}^{2+}$ solution (55-100 $\mu \mathrm{L}$ here) and repeat steps 6.8 - 6.12 until all solutions have been tested $(5.0,5.2,5.4,5.6$, $5.8,6.0)$. 
5. Lastly, re-activate the cell with activating solution (pCa4.5(3)). Repeat steps 6.8- 6.12.

\section{Incubation with kinases and phosphatases}

1. After performing the selected baseline protocol, dilute the kinase/phosphatase in Relaxing solution at the recommended concentration.

NOTE: It is recommended to carry out a dose-response curve prior to the experiment.

2. Set the temperature of the experimental wells to $20^{\circ} \mathrm{C}$.

3. Fill the experimental wells with kinase/phosphatase, relaxing solution and activating solution $(55-100 \mu \mathrm{L})$.

4. Gently move the microscope stage so that the cell becomes immersed in the well containing kinase/ phosphatase.

5. Incubate the cardiomyocyte with the kinase/phosphatase for at least 30 min or according to the manufacturers' instructions.

6. Repeat the selected baseline protocol.

\section{Finalizing the experiment}

1. Unglue the cardiomyocyte from the tips of the force transducer and motor by stretching the cell.

2. Carefully remove the glue halo from the needle tips using a cotton swab soaked in acetone.

3. Shut down the equipment.

\section{Analyzing the data}

1. Collect all files from each cardiomyocyte tested.

NOTE: Each test will correspond to one file. This means that for each $\mathrm{Ca}^{2+}$ solution or sarcomere length, there will be a corresponding file.
2. Calculate active and passive forces of a single cardiomyocyte.

1. Open the file corresponding to first activation $(\mathrm{pCa}=4.5(1))$ using a spreadsheet (Figure 3A, Appendix A in Supplementary File).

NOTE: We used a custom-made program to perform the analysis. Please see Appendix $\mathbf{A}$ in the Supplementary File.

2. Average $\approx 60$ values before and average $\approx 60$ values after the $1^{\text {st }}$ slack of the cell (when the cell is immersed in $\mathrm{Ca}^{2+}$ solution). These 2 values correspond to $\mathrm{a}$ and $\mathrm{b}$, respectively.

3. Repeat the same analysis for the $2^{\text {nd }}$ slack of the cell (when the cell is immersed in relaxing solution). These 2 values correspond to $c$ and d, respectively.

4. Calculate the difference between $a$ and $b$ (total force, Ftotal).

5. Calculate the difference between $c$ and $d$ (passive

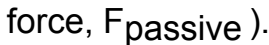

6. Calculate active force, $F_{\text {active }}=F_{\text {total }}-F_{\text {passive }}$.

7. Normalize all force values to CSA (see formula above) to obtain the total tension ( $T_{\text {total }}$ ), passive tension ( $\left.T_{\text {passive }}\right)$ and active tension ( $\mathrm{T}_{\text {active }}$ ).

8. Repeat step 9.2.1 to 9.2 .5 for the $2^{\text {nd }}$ activation $(\mathrm{pCa}=4.5(2))$.

9. Consider these values as those representing $T_{\text {total }}$, Tactive and Tpassive of the cardiomyocyte under analysis.

NOTE: The first activation of the cell with pCa4.5(1) is usually associated with alterations in cell dimensions. 
For this reason, the 2 nd activation with pCa4.5 is more accurate and is the one to be used.

10. Repeat the steps 9.2.1 to 9.2 .5 for each file/pCa tested solutions $(5.0,5.2,5.4,5.6,5.8,6.0,4.5(3))$.

3. Calculate $\mathrm{pCa} 50$ and $\mathrm{nHill}$ of a single cardiomyocyte. NOTE: For this analysis, use the non-normalized Factive values from the files 4.5(2), 5.0, 5.2, 5.4, 5.6, 5.8, 6.0 and $4.5(3)$.

1. Place in a spreadsheet file all non-normalized values of Factive for each $\mathrm{Ca}^{2+}$ solution tested (4.5(2),5.0, $5.2,5.4,5.6,5.8,6.0,4.5(3))$.

2. Calculate the correction factor $=$ Factive $[4.5(2)]-$ Factive [4.5(3)] / 7.

3. Calculate the corrected values of Factive for each $\mathrm{Ca}^{2+}$ solutions $(5.0,5.2,5.4,5.6,5.8,6.0)$ by subtracting Factive - correction factor.

4. Calculate the relative force (Frelative $)$ for each $\mathrm{Ca}^{2+}$ solutions by normalizing each Factive values by the corresponding corrected value.

NOTE: The Frelative [4.5(3)] should equal 1. Each experimental protocol begins and ends with a control activation at saturating $\mathrm{Ca}^{2+}$ concentration $(\mathrm{pCa}$ 4.5(2) and 4.5(3)). This allows force normalization and assessment of the rundown of the preparations through the comparison of changes in maximal $\mathrm{Ca}^{2+}$-activated force $\left(\mathrm{F}_{\max }\right)$. If at the end of the experimental protocol, the cardiomyocyte produces less than at least $70 \%$ of the maximum force of the first contraction, that cell/measurement should be excluded from the analysis.
5. Use the Frelative and the corresponding pCa values to fit to a sigmoidal curve with the following equation $\mathrm{F}(\mathrm{Ca})=\mathrm{Ca}^{\text {nHill }} /\left(\mathrm{Ca} 50^{\text {nHill }}+\mathrm{Ca}^{\text {nHill }}\right)$.

6. Extrapolate $\mathrm{pCa}$ and $\mathrm{nHill}$ values from the equation above mentioned.

4. Calculate the rate of force redevelopment (ktr) of a single cardiomyocyte.

1. Perform a fit to the curve that corresponds to the values immediately after the $1^{\text {st }}$ cell slack.

2. Calculate the slope of the curve and this value will correspond to the rate of force redevelopment.

3. Repeat step 9.4.1 and 9.4.2 for each $\mathrm{Ca}^{2+}$ solution. NOTE: A poor curve fit will be obtained for the lowest Ca-solutions ( $\mathrm{R}$ squared $\leq 0.90$ ).

\section{Representative Results}

Functional permeabilized cardiomyocytes should appear uniform and with a consistent striation pattern throughout the entire experiment. Although a certain degree of deterioration and force decrease is expected after prolonged experiments, the values of active tension should be relatively stable. Cells showing clear signs of striation loss or significant force decrease $\left(<15 \mathrm{kN} \cdot \mathrm{m}^{-2}\right.$ or $<80 \%$ of its initial active force) should be excluded. Table 6 displays the normal values expected for the most important parameters derived from rodents, pigs and human samples. 
The parameters obtained depend mainly on the chosen protocol. Figure $\mathbf{5}$ shows representative force traces of 3 , out of 8 , force recordings needed to carry out a protocol of myofilaments $\mathrm{Ca}^{2+}$-sensitivity. By transferring the cell to a well containing the activating solution, the cardiomyocyte starts to develop force until it reaches a plateau. After a quick slack test (duration of $1 \mathrm{~ms}$ ), whereby the cardiomyocyte shortens to $80 \%$ of its length, we obtain the baseline values of zero force. After the slack test, the cell continues to develop force as it is immersed in the activating solution. Total force ( $\left.F_{\text {total }}\right)$ is calculated by subtracting the plateau value from the minimal value. The slope of the last part of this curve gives us the value of the rate of force redevelopment (ktr) (Figure 6), which is a measure of the apparent rate of cross-bridge attachment and detachment (fapp and gaap $)^{10}$. When the ktr $R^{2}$ value is $<0.90$ the ktr value should be excluded and usually this happens at lower $\mathrm{Ca}^{2+}$ concentrations $(\mathrm{pCa}$ 5.6, 5.8 and 6.0). After transferring the cell back to a well containing the relaxing solution, the cell relaxes and its force drops. Passive force ( $\left.F_{\text {passive }}\right)$ is calculated by subtracting the minimal value (obtained after a prolonged cell shortening) to this new value of force. Active force results from the difference between $F_{\text {total }}$ and $F_{\text {passive }}$.

The maximal active and passive force that characterizes a cardiomyocyte is the one derived from the second cell activation with a saturating $\mathrm{Ca}^{2+}$-solution $(\mathrm{pCa}=4.5)$. The first activation is usually discarded as the sarcomere length often needs to be readjusted.
To carry out a myofilament $\mathrm{Ca}^{2+}$-sensitivity protocol, it is necessary to perform at least 9 activation tests $(4.5 ; 4.5$; $5.2 ; 5.6 ; 6.0 ; 5.0 ; 5.4 ; 5.8$ and 4.5$)$. This sequence is merely exemplifying but should always start with 4.5 (twice) and end with 4.5. The programming of the data-acquisition software for a myofilament $\mathrm{Ca}^{2+}$-sensitivity protocol is depicted in Figure 1 of the Supplementary File.

After calculating active force for all these activation solutions, check if the last activation yielded more than $80 \%$ of the initial maximal force (otherwise this cell results should be discarded, as mentioned above). To correct for the decline in $F_{\max }$ during the experimental series, the interpolated $F_{\text {max }}$ values can be used to normalize the data points. The normalized data can be fit to a sigmoidal curve with the following equation $\mathrm{F}(\mathrm{Ca})=\mathrm{Ca}^{\text {nHill }} /\left(\mathrm{Ca} 50^{\mathrm{nHill}}+\mathrm{Ca}^{\text {nHill }}\right)$. The parameter values obtained represent the calcium sensitivity (Ca50, which can be converted into $\mathrm{pCa} 50$ ) and cooperativity (nHill).All force values can be converted to tension values after normalizing to the cross-sectional area. Besides myofilament $\mathrm{Ca}^{2+}$ sensitivity and the length-dependent activation protocols, other tests can be performed. Such is the case of sarcomere length dependencies of Tactive, Tpassive (Figure 7), and cardiomyocyte residual force. Residual force recordings are calculated from the initial force recovery ( $\mathrm{pCa} 4.5$ ) reached after the length change of the cell $(80 \%)$ and normalized to each total steady-state force reached before length change ${ }^{11}$. Increase in residual force is usually indicative of cross-bridges with slow detachment kinetics and higher stiffness. 
Finally, we should stress that this technique can be its membranes. The way the cardiomyocytes are isolated carried out in skinned cardiomyocytes extracted mechanically impacts significantly the results derived from this technique. from frozen or freshly collected samples, as well as Figure 8 shows the differences observed among the three isolated enzymatically followed by the permeabilization of isolation procedures.

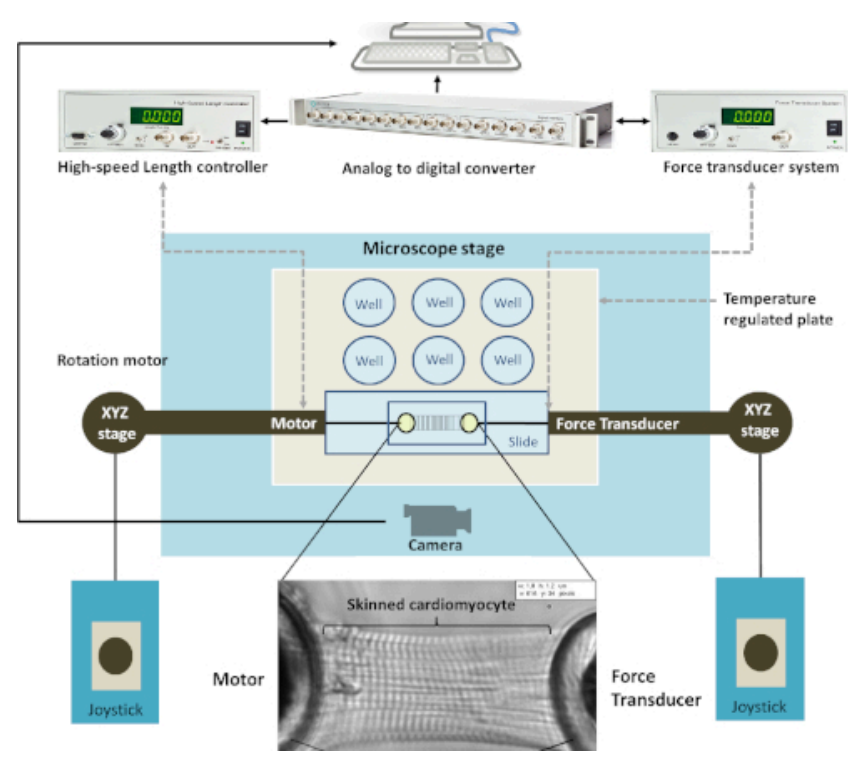

Figure 1: Integrated scheme of the testing apparatus. The testing apparatus includes the microscope, the micromanipulators and the associated computer. The bottom of the figure shows a skinned cardiomyocyte glued between the motor and the force transducer. Please click here to view a larger version of this figure. 

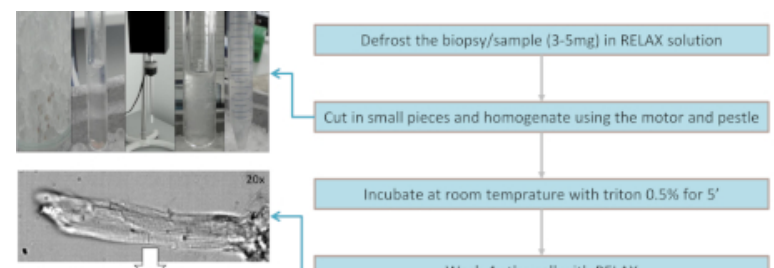
N14.1P

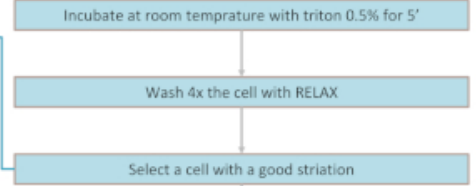

Mix (up and down

Centrifuge $\left(3486,4^{\circ} \mathrm{C}\right.$ for $\left.1^{\prime}\right)$

Select a cell with a good striation

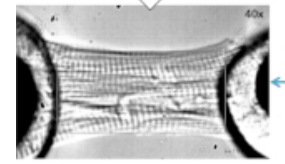

Glue the cell ends to the motor and the transducer

Perform the selected protocol

$\left[\mathrm{Ca}^{2}\right]$ sensitivity

Length-1epe

Figure 2: Flow chart of the protocol of cell isolation, permeabilization and gluing. The upper left corner image is composed of 4 images showing pieces of the heart sample in the RELAX-ISO solution (A) in a Petri dish, (B) in a tube used for mechanical homogenization of tissue, (C) the homogenizer, (D) the tissue immediately after homogenization and (E) when it is in a tube for Triton permeabilization. Please click here to view a larger version of this figure.

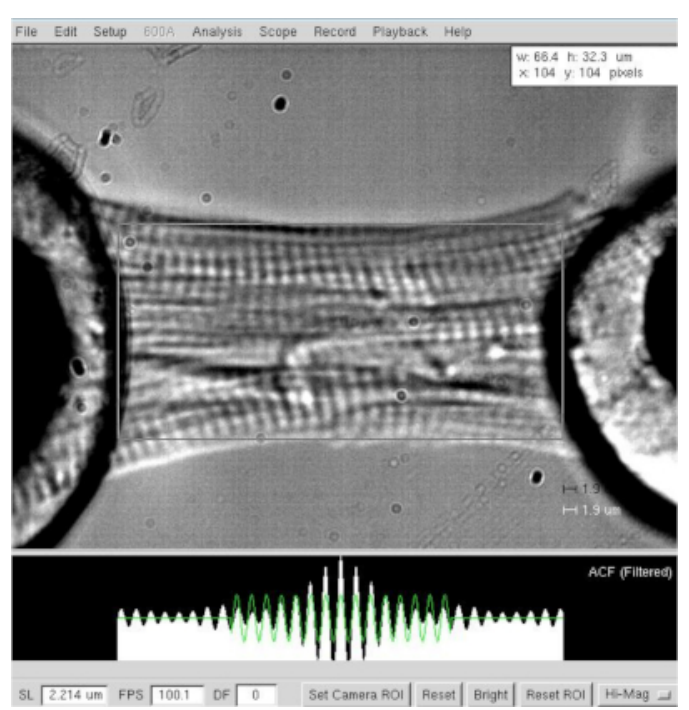

Figure 3: Determination of length and sarcomere length of a skinned cardiomyocyte. Cell length and width determination at a sarcomere length of $\approx 2.2 \mu \mathrm{m}$. Please click here to view a larger version of this figure. 
A. Sarcomere length $=1.8 \mu \mathrm{m}$

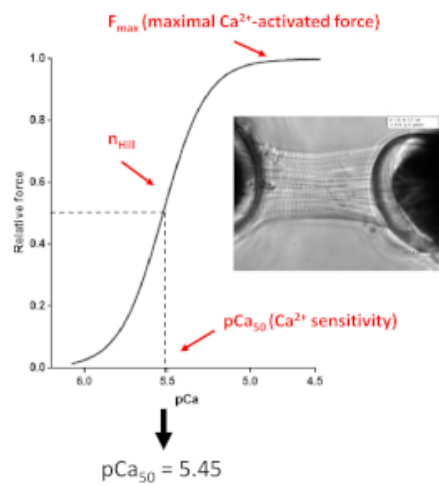

B. Sarcomere length $=2.2 \mu \mathrm{m}$

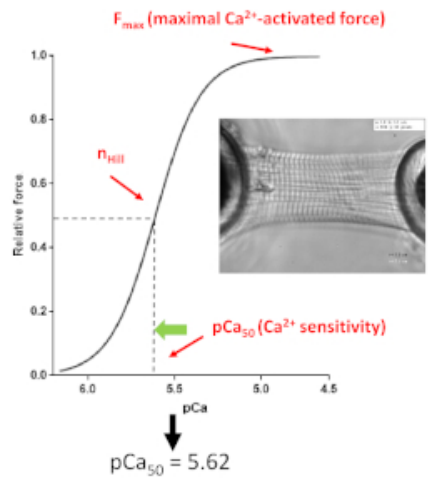

Figure 4: Length-dependent activation protocol (mimics the Frank-starling mechanism in vitro). Representative force traces and parameters derived from myofilaments' $\mathrm{Ca}^{2+}$ sensitivity protocols performed before $(\mathbf{A}, 1.8 \mu \mathrm{m})$ and after stretching a cardiomyocyte up to $2.2 \mu \mathrm{m}$ (B). Please click here to view a larger version of this figure.

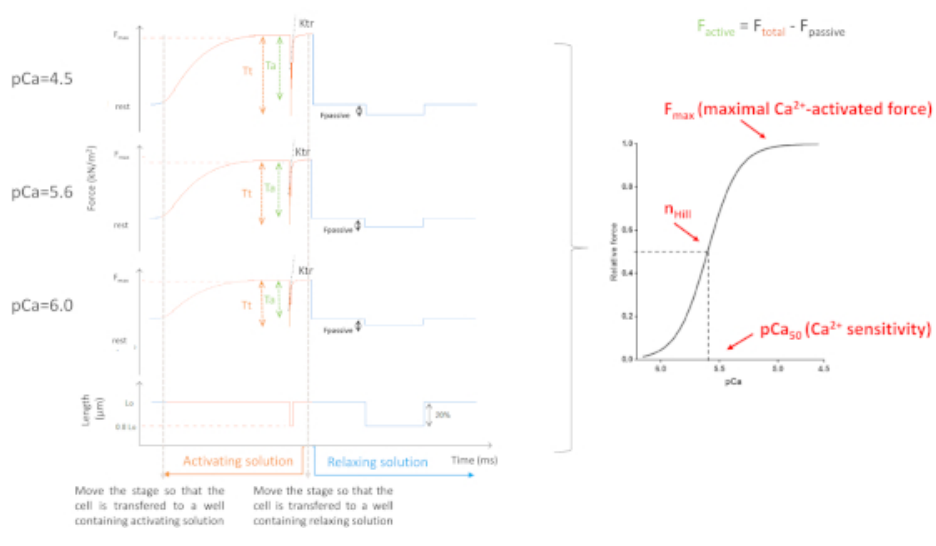

Figure 5: Myofilaments $\mathrm{Ca}^{2+}$-sensitivity protocol. Representative force traces and derived parameters. For the sake of simplicity, only 3 out of 8 force curves are depicted. Namely a cardiomyocyte activated with the saturating, an intermediate and the lowest $\mathrm{Ca}^{2+}$-containing solution (4.5, 5,6 and 6.0, respectively). Please click here to view a larger version of this figure. 

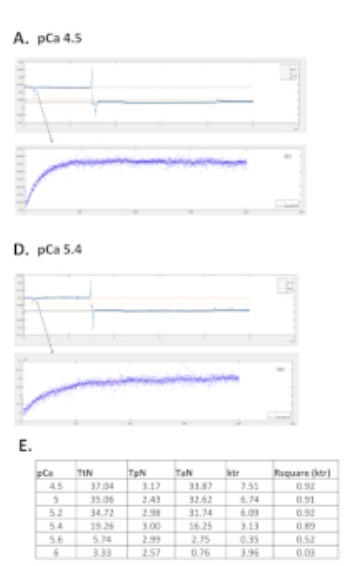

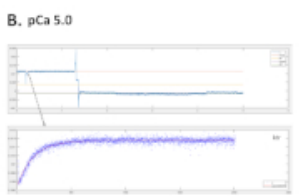

E. pCa 5.6

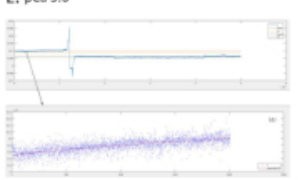

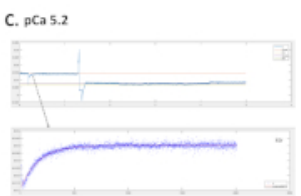

F. pca6.0

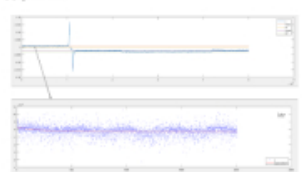

Figure 6: Representative traces from a mice cardiac cell activated at different calcium solutions and the respective ktr fit curve. (A) pCa 4.5; (B) pCa 5.0; (C) pCa 5.2; (D) pCa 5.4; (E) pCa 5.6; (F) pCa 6.0 and E values for total, passive and active tension, ktr value and Rsquare for ktr fit. Please click here to view a larger version of this figure.
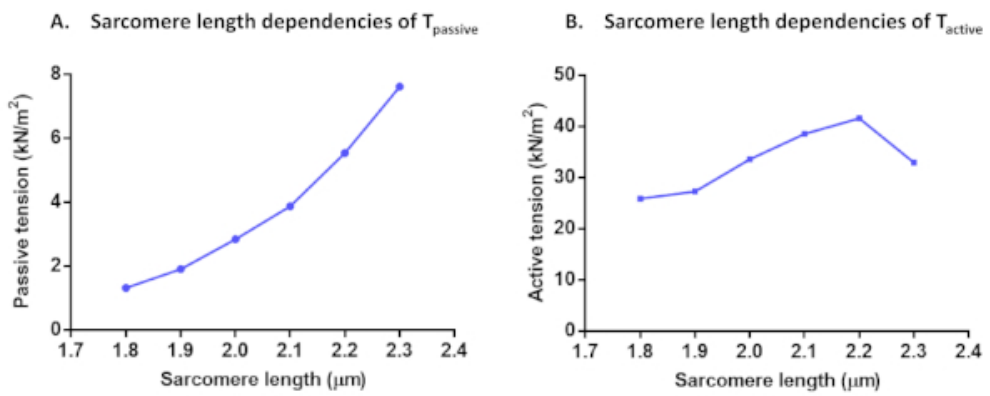

Figure 7: Protocols of sarcomere length dependencies of Tpassive (A) and Tactive (B). Passive tension and active tension were calculated in a single cardiomyocyte at a sarcomere length of $1.8 \mu \mathrm{m}$ to $2.3 \mu \mathrm{m}$. Please click here to view a larger version of this figure. 

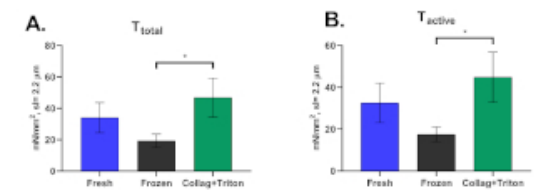

D.

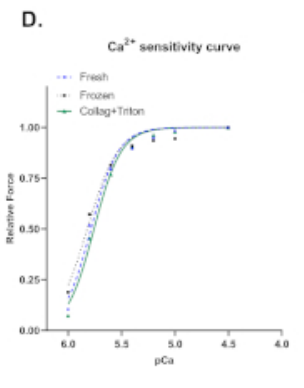

E.

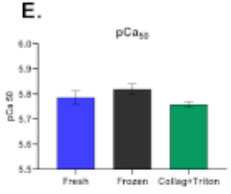

III

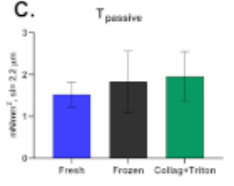

F.

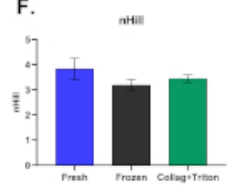

III

Figure 8: Representative results for cardiomyocytes mechanically isolated from fresh ("Fresh") and frozen myocardial samples ("Frozen") as well as from collagenase digested heart (modified Langgendorf technique) with posterior permeabilization with Triton ("Collag+Triton"). Values of (A) Total tension, (B) Active Tension and (C) Pasisve Tension from cardiomyocytes activated with pCa 4.5 solution at a sarcomere length of $\approx 2.2 \mu \mathrm{m}$. (D) Calcium sensitivity curve and the respective values for (E) pCa50 and (F) nHill. (G) Residual Force and (H) ktr values calculated at maximum activation solution ( $\mathrm{pCa} 4.5$ ). Please click here to view a larger version of this figure.

Supplemental File. Please click here to download this file.

\begin{tabular}{|c|c|c|c|c|c|}
\hline Store at & Stock solutions & [M] & Final volume $(\mathrm{mL})$ & Weight/ volume & Notes \\
\hline $4^{\circ} \mathrm{C}$ & $\begin{array}{c}\text { Potassium } \\
\text { hydroxide }(\mathrm{KOH})\end{array}$ & 1 & 100 & $5.611 \mathrm{~g}$ & To adjust pH \\
\hline $4^{\circ} \mathrm{C}$ & $\begin{array}{c}\text { Potassium } \\
\text { hydroxide }(\mathrm{KOH})\end{array}$ & 5 & 50 & $14.03 \mathrm{~g}$ & To adjust $\mathrm{pH}$ \\
\hline $4^{\circ} \mathrm{C}$ & BES & 1 & 50 & $10.66 \mathrm{~g}$ & \\
\hline $4^{\circ} \mathrm{C}$ & Propionic acid & 1 & 100 & $7.483 \mathrm{~mL}$ & $\begin{array}{l}\text { Adjust the } \mathrm{pH} \\
\text { to } 7.0 \text { with } 5 \mathrm{M} \\
\text { or } 1 \mathrm{M} \mathrm{KOH}\end{array}$ \\
\hline \multirow[t]{2}{*}{$4^{\circ} \mathrm{C}$} & $\begin{array}{c}\text { CaEGTA } \\
\text { composed of: }\end{array}$ & 0.1 & 100 & & \multirow{2}{*}{$\begin{array}{l}\text { Mix and heat the } \\
\text { solution to } 60^{\circ} \mathrm{C} \text { for } \\
\text { more than } 1 \text { hour. }\end{array}$} \\
\hline & $-\mathrm{CaCO}_{3}$ & 0.1 & & $1.001 \mathrm{~g}$ & \\
\hline
\end{tabular}




\begin{tabular}{|l|l|l|l|}
\cline { 3 - 4 } & 0.1 & 3.804 & $\begin{array}{c}\text { Adjust the } \mathrm{pH} \text { to } \\
5-6 \text { with } 1 \mathrm{M} \mathrm{KOH} .\end{array}$ \\
\hline
\end{tabular}

Table 1: Instructions for stock solution preparation.

\begin{tabular}{|c|c|c|}
\hline $\begin{array}{c}\text { RELAX-ISO (for } \\
\text { cardiomyocytes' isolation) }\end{array}$ & {$[\mathrm{mM}]$} & Weight \\
\hline $\mathrm{Na}_{2} \mathrm{ATP}$ & 5.95 & $3.28 \mathrm{~g}$ \\
\hline $\mathrm{MgCl}_{2} \cdot 6 \mathrm{H}_{2} \mathrm{O}$ & 6.04 & $1.23 \mathrm{~g}$ \\
\hline Tritiplex (EGTA) & 2 & $0.76 \mathrm{~g}$ \\
\hline $\mathrm{KCl}$ & 139.6 & $10.41 \mathrm{~g}$ \\
\hline Imidazole & 10 & $0.68 \mathrm{~g}$ \\
\hline
\end{tabular}

Table 2: Instructions for Relax-ISO solution preparation.

\begin{tabular}{|c|c|c|}
\hline $\begin{array}{c}\text { Activating solution (for } \\
\text { the measurements) }\end{array}$ & [mM] & Weight / volume \\
\hline Na2 ATP & 5.97 & $0.823 \mathrm{~g}$ \\
\hline MgCl 1M & 6.28 & $1.57 \mathrm{~mL}$ \\
\hline Propionic acid & 40.64 & $25 \mathrm{~mL}$ \\
\hline BES & 100 & $17.5 \mathrm{~mL}$ \\
\hline CaEGTA (stock solution & 7 & $0.925 \mathrm{~g}$ \\
\hline
\end{tabular}

Table 3: Instructions for activating solution preparation. 


\begin{tabular}{|c|c|c|}
\hline $\begin{array}{c}\text { Relaxing solution (for } \\
\text { the measurements) }\end{array}$ & [mM] & Weight / volume \\
\hline Na2 ATP & 5.89 & $0.325 \mathrm{~g}$ \\
\hline MgCl 1M & 6.48 & $0.65 \mathrm{~mL}$ \\
\hline Propionic acid & 40.76 & $4.08 \mathrm{~mL}$ \\
\hline BES & 100 & $10 \mathrm{~mL}$ \\
\hline Titriplex (EGTA) & 6.97 & $0.265 \mathrm{~g}$ \\
\hline Na2 PCr & 14.5 & $0.370 \mathrm{~g}$ \\
\hline
\end{tabular}

Table 4: Instructions for relaxing solution preparation.

\begin{tabular}{|c|c|c|}
\hline $\mathrm{pCa}=-\mathrm{Log}\left[\mathrm{Ca}^{2+}\right]$ & $\begin{array}{c}\text { Relaxing (pCa=9.0) } \\
\mathrm{mL}\end{array}$ & $\begin{array}{c}\text { Ativating (pa=4.5) } \\
\mathrm{mL}\end{array}$ \\
\hline 5 & 0.86 & 39.14 \\
\hline 5.1 & 1.2 & 38.80 \\
\hline 5.2 & 1.54 & 38.46 \\
\hline 5.3 & 2 & 38.00 \\
\hline 5.4 & 2.51 & 37.49 \\
\hline 5.5 & 3.14 & 36.86 \\
\hline 5.6 & 3.89 & 36.11 \\
\hline 5.7 & 4.8 & 35.20 \\
\hline 5.8 & 5.89 & 34.11 \\
\hline 5.9 & 7.14 & 32.86 \\
\hline 6 & 8.57 & 31.43 \\
\hline
\end{tabular}

Table 5: Instructions for $\mathrm{pCa}$ solutions preparation. 


\begin{tabular}{|c|c|c|c|}
\hline Parameter & Rodent & Pig & Human \\
\hline $\begin{array}{c}\text { Active tension, } \\
\mathrm{kN} \cdot \mathrm{m}^{-2}(\text { at } 2.2 \mu \mathrm{m})\end{array}$ & $17-28$ & $19-40$ & 196 \\
\hline $\begin{array}{c}\text { Passive tension, } \\
\left.\mathrm{kN} . \mathrm{m}^{-2} \text { (at } 2.2 \mu \mathrm{m}\right)\end{array}$ & $3.6-5.5$ & $1.9-6.8$ & $5.83-5.82$ \\
\hline $\mathrm{pCa50}$ & $5.58-5.64$ & $5.40-5.50$ & $2.99-3.10$ \\
\hline $\mathrm{nHill}$ & $2.60-2.76$ & $2.95-3.36$ & $0.90-2.00$ \\
\hline $\mathrm{ktr}, \mathrm{s}^{-1}$ & $4.00-8.00$ & $1.00-3.00$ & \\
\hline
\end{tabular}

Table 6: Typical parameters and indices derived from single permeabilized cardiomyocytes from rodents, pigs and humans. Adapted from ${ }^{12}$. 


\begin{tabular}{|c|c|c|}
\hline Problem & Possible reason & Solution \\
\hline \multirow[t]{2}{*}{$\begin{array}{c}\text { The cardiomyocyte detaches } \\
\text { during maximal activation }\end{array}$} & $\begin{array}{l}\text { Insufficient gluing time; The } \\
\text { glue is old and has dried }\end{array}$ & $\begin{array}{l}\text { Increase the time of the gluing step; } \\
\text { consider opening a new glue tube. }\end{array}$ \\
\hline & $\begin{array}{l}\text { There is Triton } ® \text { in the cell } \\
\text { suspension solution, which } \\
\text { can no longer be removed }\end{array}$ & $\begin{array}{c}\text { Repeat the extraction procedure } \\
\text { with one or two additional } \\
\text { Triton® wash out steps }\end{array}$ \\
\hline $\begin{array}{l}\text { The cardiomyocyte has low } \\
\text { force under control conditions }\end{array}$ & $\begin{array}{l}\text { The extraction went wrong } \\
\text { and delivered low-quality cells }\end{array}$ & $\begin{array}{l}\text { Increase the sample size and do } \\
\text { a new extraction. If the problem } \\
\text { persists is probably due to improper } \\
\text { sample collection - discard this sample }\end{array}$ \\
\hline \multirow{3}{*}{$\begin{array}{l}\text { The cell is visibly contracting } \\
\text { but no force is recorded; The } \\
\text { cell has unusual force values }\end{array}$} & The force transducer is off & Turn it on \\
\hline & $\begin{array}{l}\text { The force transducer } \\
\text { is not well calibrated }\end{array}$ & $\begin{array}{l}\text { Calibrate the force transducer using } \\
\text { a set of known weights (check the } \\
\text { manufacturer's instruction manual). }\end{array}$ \\
\hline & The force transducer needle is loose & $\begin{array}{l}\text { Glue the needle again using } \\
\text { crystal bond } 509 \text { or jewelers wax. }\end{array}$ \\
\hline \multirow[t]{3}{*}{$\begin{array}{c}\text { The striation pattern is not good enough } \\
\text { to determine the sarcomere length }\end{array}$} & Insufficient light & $\begin{array}{l}\text { Increase microscope light or move } \\
\text { the cell back to the coverslip and } \\
\text { assess sarcomere length again } \\
\text { (the wells have lower light intensity) }\end{array}$ \\
\hline & $\begin{array}{l}\text { The extraction went wrong } \\
\text { and delivered low-quality cells }\end{array}$ & $\begin{array}{l}\text { Increase the sample size } \\
\text { and do a new extraction }\end{array}$ \\
\hline & Needles' tips are not in the same plane & $\begin{array}{l}\text { Using micromanipulators, adjust } \\
\text { the needles' tips up or down until } \\
\text { finding a focused sarcomeres }\end{array}$ \\
\hline \multirow[t]{2}{*}{$\begin{array}{l}\text { No length and/or force } \\
\text { variation during acquisition }\end{array}$} & $\begin{array}{c}\text { The motor or the force } \\
\text { transducer are off }\end{array}$ & Turn them on \\
\hline & $\begin{array}{c}\text { The motor is broken and not } \\
\text { producing cell shortening }\end{array}$ & $\begin{array}{l}\text { Replace it or try to calibrate } \\
\text { it using a function generator }\end{array}$ \\
\hline $\begin{array}{l}\text { Too much noise on the } \\
\text { acquisition recordings }\end{array}$ & Too much air flow around the equipment & $\begin{array}{l}\text { Protect the equipment } \\
\text { from the direct air flow }\end{array}$ \\
\hline
\end{tabular}




\begin{tabular}{|c|c|c|}
\hline & $\begin{array}{l}\text { Too many vibrations } \\
\text { around the equipment }\end{array}$ & $\begin{array}{l}\text { A stabilization table is advisable. } \\
\text { Even then, it is recommended } \\
\text { to remove any equipment that } \\
\text { might have a compressor or } \\
\text { emit vibrations (freezer, fridges) }\end{array}$ \\
\hline $\begin{array}{l}\mathrm{Ca}^{2+} \text {-sensitivity curve has strange } \\
\text { values and the force values } \\
\text { do not increase with }\left[\mathrm{Ca}^{2+}\right] \text {. }\end{array}$ & $\begin{array}{l}\text { The mixture of activating and relaxing } \\
\text { solution was not done properly (check } \\
3.10 \text { to } 3.14 \text { of the methods section, } \\
\text { possibly due to insufficient mixing) }\end{array}$ & $\begin{array}{l}\text { Defrost the vials with the same } \\
\text { concentration, collect all vial's content } \\
\text { in the same beaker, mix with a stirrer } \\
\text { and divide them again. Test these } \\
\text { solutions again in a new cell. If this } \\
\text { does solve the problem, prepare a new } \\
\text { batch of } \mathrm{Ca}^{2+} \text {-containing solutions }\end{array}$ \\
\hline
\end{tabular}

Table 7: Troubleshooting table.

\section{Discussion}

In vitro assessment of cardiac function using skinned cardiomyocytes represents an important technique to clarify the modifications occurring at cardiomyocyte level in physiological (e.g., stretch) and pathological context (e.g., ischemia). This methodology has several advantages such as requiring a minimal amount of myocardium to assess function in cardiomyocytes obtained from defrosted samples; using cardiomyocytes from a wide range of species (mice ${ }^{13}$, rat $^{1,14,15}$, rabbit $^{16}, \operatorname{pig}^{17}, \operatorname{dog}^{18}$, guinea $\operatorname{pig}^{19}$ and human ${ }^{20}$ ) and different cardiac locations, including the atria, left and right ventricles or a specific region of the infarcted heart. Moreover, this technique allows delivering specific concentrations of $\mathrm{Ca}^{2+}$ and energy (ATP) while measuring the function of regulatory and contractile structures in their native configuration.

Despite the simplicity of this technique, there are some critical steps. It is essential to guarantee the quality of each step from the beginning, including sample collection.
Myofilament proteins are susceptible to proteases ${ }^{21}$. Thus it is mandatory to store samples in liquid nitrogen immediately after its collection. Fresh samples, which were not previously frozen, will develop significantly higher forces, so it is not advisable to mix measurement done in fresh and frozen samples in the same protocol. The second most critical step is the cardiomyocytes' extraction. During this procedure, it is crucial to maintain the sample on ice most of the time. A protease inhibitor cocktail can be used to reduce the risk of protein degradation during the extraction/permeabilization ${ }^{22}$. Thirdly, samples should be cut in smaller pieces using precise scalpel movements since we noted reduced quality cardiomyocytes when this step was disregarded. Another critical step is washing the cardiomyocytes since it is difficult to have the right balance between washing out Triton (permeabilizes the cell but promotes its ungluing) and keeping as many cells in the supernatant as possible. It is important to first try the extraction and number of washouts for each sample, species or protocol. For instance, in our 
hands, we noted that ZSF1 obese rat tissue extractions have a "fatty" aspect, which made these cells more slippery during the gluing but not more difficult to measure. The way we circumvent this problem was by performing more experiments to have a reasonable number of cells per animal. Moreover, it is crucial to select a good cell to glue, namely with good striation and reasonable length. If the cardiomyocyte does not have these features, it will mostly detach from the needle tips or develop no/low force. It is also important to use the correct glue for cardiomyocyte attachment, considering the time of gluing and its efficacy to glue the cell to the needle. In our hands, the silicone glue (Table of Materials) cures fast (10-15 min) and strong enough. Finally, the last critical step is related with carefully lifting the cardiomyocyte $5 \mathrm{~min}$ after gluing the cell (to avoid gluing the cell to the coverslip) and before moving it to the wells (to avoid the cell to be dragged by the microscope stage). Table 7 summarizes the troubleshooting associated with this technique, its underlying causes and possible solutions to overcome frequent problems.

The major limitation of this method is that it cannot answer all the questions related to the myofilament contractility, such as how fast the myofilaments activate/deactivate. In the in vivo setting, membrane depolarization, intracellular $\mathrm{Ca}^{2+}$ increase and its diffusion to myofilaments need to occur for the myocytes to contract, whereas in skinned cardiomyocytes $\mathrm{Ca}^{2+}$ diffusion to myofilaments occurs immediately when the cell is submerged in the $\mathrm{Ca}^{2+}$ solution. This faster rate of $\mathrm{Ca}^{2+}$ diffusion will bias myofilaments activation/deactivation analysis $^{23}$.

These experiments are influenced by different factors, including the temperature, solution $\mathrm{pH}$, mechanical perturbation (slack-re-stretch vs. slack) and cell attachment procedures (pin tie vs. glue), all of these variables accounting for literature discrepancies in terms of ktr and the sarcomere length-dependent increase in force ${ }^{4,12}$.

Future progress of the technique includes performing functional studies in intact rather than permeabilized cardiomyocytes. This technique has the disadvantage of relying on cardiomyocytes freshly isolated (not previously frozen). Another important issue not directly related to this methodology but that may significantly impact it is related to the maximal period of sample frozen storage. Specifically, it is mandatory to establish the degree of myofilament degradation throughout storage time (i.e., for how long frozen samples can be stored in order to assure good quality functional data derived from the extracted cardiomyocytes).

\section{Disclosures}

The authors have no conflict of interest.

\section{Acknowledgments}

The authors thank Portuguese Foundation for Science and Technology (FCT), European Union, Quadro de Referência Estratégico Nacional (QREN), Fundo Europeu de Desenvolvimento Regional (FEDER) and Programa Operacional Factores de Competitividade (COMPETE) for funding UnIC (UID/IC/00051/2013) research unit. This project is supported by FEDER through COMPETE 2020 - Programa Operacional Competitividade E Internacionalização (POCI), the project DOCNET (NORTE-01-0145-FEDER-000003), supported by Norte Portugal regional operational programme (NORTE 2020), under the Portugal 2020 partnership agreement, through the European Regional Development Fund (ERDF), the project NETDIAMOND (POCI-01-0145-FEDER-016385), supported by European Structural And Investment Funds, 
Lisbon's regional operational program 2020. Patrícia Rodrigues was funded by FCT (SFRH/BD/96026/2013) and João Almeida-Coelho was by Universidade do Porto/ FMUP and FSE-Fundo Social Europeu, NORTE 2020Programa Operacional Regional do Norte, (NORTE-08-5369FSE-000024-Programas Doutorais).

\section{References}

1. Leite-Moreira, A. M. et al. Stretch-induced compliance: a novel adaptive biological mechanism following acute cardiac load. Cardiovascular Research. 114 (5), 656-667 (2018).

2. Falcao-Pires, I., Fontes-Sousa, A. P., Lopes-Conceicao, L., Bras-Silva, C., Leite-Moreira, A. F. Modulation of myocardial stiffness by $\beta$-adrenergic stimulation - its role in normal and failing heart. Physiological Research. 60 (4), 599-609 (2011).

3. Cokkinos, D. V. in Introduction to Translational Cardiovascular Research. 371-387 Springer International Publishing, (2015).

4. van der Velden, J., Stienen, G. J. M. Cardiac Disorders and Pathophysiology of Sarcomeric Proteins. Physiological Reviews. 99 (1), 381-426 (2019).

5. Garnier, D. Attachment procedures for mechanical manipulation of isolated cardiac myocytes: a challenge. Cardiovascular Research. 28 (12), 1758-1764 (1994).

6. Brady, A. J. Mechanical properties of isolated cardiac myocytes. Physiological Reviews. 71 (2), 413-428 (1991).

7. Falcao-Pires, I., Leite-Moreira, A. F. in Introduction to Translational Cardiovascular Research. (ed Dennis V. Cokkinos) Ch. 20, 371-387 Springer, Cham, (2015).
8. Liang, W. Teaching calcium-induced calcium release in cardiomyocytes using a classic paper by Fabiato. Advances Physiology Education. 32 (1), 1-10 (2008).

9. Roche, S. M., Gumucio, J. P., Brooks, S. V., Mendias, C. L., Claflin, D. R. Measurement of Maximum Isometric Force Generated by Permeabilized Skeletal Muscle Fibers. Journal of Visualized Experiments. (100), e52695 (2015).

10. Huxley, A. F. Muscle structure and theories of contraction. Progress Biophysics and Biophysical Chemistry. 7, 255-318 (1957).

11. Sequeira, V. et al. Synergistic role of ADP and $\mathrm{Ca}(2+)$ in diastolic myocardial stiffness. Journal Physiology. 593 (17), 3899-3916 (2015).

12. Edes, I. F. et al. Rate of tension redevelopment is not modulated by sarcomere length in permeabilized human, murine, and porcine cardiomyocytes. American Journal Physiology Regulatory Integrative Comparative Physiology. 293 (1), R20-29 (2007).

13. King, N. M. et al. Mouse intact cardiac myocyte mechanics: cross-bridge and titin-based stress in unactivated cells. Journal General Physiology. 137 (1), 81-91 (2011).

14. Hamdani, N. et al. Myocardial titin hypophosphorylation importantly contributes to heart failure with preserved ejection fraction in a rat metabolic risk model. Circulation Heart Failure. 6 (6), 1239-1249 (2013).

15. Miranda-Silva, D. et al. Characterization of biventricular alterations in myocardial (reverse) remodelling in aortic banding-induced chronic pressure overload. Scientific Reports. 9 (1), 2956 (2019). 
16. Rodrigues, P. G. et al. Early myocardial changes induced by doxorubicin in the nonfailing dilated ventricle. American Journal Physiology Heart Circulatory Physiology. 316 (3), H459-H475 (2019).

17. van der Velden, J. et al. Alterations in myofilament function contribute to left ventricular dysfunction in pigs early after myocardial infarction. Circulation Research. 95 (11), e85-95 (2004).

18. Wakili, R. et al. Multiple potential molecular contributors to atrial hypocontractility caused by atrial tachycardia remodeling in dogs. Circulation: Arrhythmia Electrophysiology. 3 (5), 530-541 (2010).

19. Ait Mou, Y., le Guennec, J. Y., Mosca, E., de Tombe, P. P., Cazorla, O. Differential contribution of cardiac sarcomeric proteins in the myofibrillar force response to stretch. Pflugers Archiv. 457 (1), 25-36 (2008).

20. Falcao-Pires, I. et al. Diabetes mellitus worsens diastolic left ventricular dysfunction in aortic stenosis through altered myocardial structure and cardiomyocyte stiffness. Circulation. 124 (10), 1151-1159 (2011).

21. Lim, C. C. et al. Anthracyclines induce calpain-dependent titin proteolysis and necrosis in cardiomyocytes. Journal Biology Chemistry. 279 (9), 8290-8299 (2004).

22. Woulfe, K. C. et al. A Novel Method of Isolating Myofibrils From Primary Cardiomyocyte Culture Suitable for Myofibril Mechanical Study. Frontiers Cardiovascular Medicine. 6, 12 (2019).

23. Ait Mou, Y., Bollensdorff, C., Cazorla, O., Magdi, Y., de Tombe, P. P. Exploring cardiac biophysical properties. Global Cardiology Science Practice. 2015, 10 (2015). 